\title{
Revistas de Arquitectura, el nuevo escenario del siglo $\mathrm{xxI}$
}

ARQTO. RAMÓN GUTIÉRREZ Director del CEDODAL
$\mathrm{Ni}$ caben dudas de que la arquitectura atinoamericana del siglo xx recogerá las fuentes de su conocimiento en las más de 500 revistas que se editaron entonces en nuestro continente. Son ellas, el mejor reflejo de lo realizado que fue ponderado y criticado en su momento o en el tiempo histórico, pero también testimonian aquello que se pensó hacer y no llegó a concretarse y las ideas, opiniones, teorías y debates que obras y postulados generaron.

Marcadas por las dificultades de economías precarias buena parte de estas revistas tuvieron corta vida expresiva del voluntarismo de sus editores o de las limitaciones de su capacidad distributiva. Otras, expresión de corporaciones institucionales, naufragaron en los cambios de directivas que con demasiada frecuencia buscaron mostrar su originalidad cambiando formato, diseño y hasta título para señalar su incontrastable presencia diferenciadora.

En muchas oportunidades, bibliotecarios norteamericanos y europeos me han señalado que el problema principal de las revistas de arquitectura latinoamericanas reside justamente en estas incertidumbres. La carencia de una frecuencia sistemática de aparición, las variaciones de tamaño, los cambios de título e inclusive de numeración que llevan a una fragmentación e incomprensión por parte de quienes ven la revista como una serie de aportes consolidados por una acción institucional.

Nuestro siglo xx culminó con un puñado de revistas que superaron el centenar de ejemplares, la mayoría de ellas de carácter comercial o institucional: ACROPOLE, MÓdULO, Projeto y Au en Brasil, Revista de Arquitectura, Nuestra Arquitectura, Cacya y Summa en Argentina, ProA en Colombia, ARQUITECTO Peruano en Perú, Revista de Arquitectura en Uruguay, Arquitectura Cuba en Cuba y ARquiteCtura en México. Casi todas ellas han desaparecido y solamente persisten la Revista de Arquitectura de la Sociedad Central de Arquitectos de Buenos Aires, una nueva Summat que comenzó una nueva etapa con nueva numeración, Projeto y Au en Brasil y en estado latente las revistas de las Sociedades de Arquitectos de Uruguay y Cuba que, sin haber labrado acta de defunción, dejaron de aparecer sistemáticamente. Estamos en este caso hablando de las revistas más antiguas que teóricamente subsisten, pues comenzaron a editarse en 1914 y 1917, respectivamente.

Cabe preguntarse cómo hacían unas pocas decenas de arquitectos en el Uruguay o en Cuba en la segunda década del siglo xx para editar una revista mensualmente durante 25 años, cuando hoy las mismas instituciones con miles de arquitectos son incapaces de producir una revista al año...

Nuestro siglo XXI comienza entonces con el cierre de revistas que marcaron una trayectoria muy rica en la arquitectura latinoamericana: PrOA en Colombia que aparecía desde 1946 y Summa en Argentina que lo hacía desde 1963. En el devenir desaparecieron también revistas muy ligadas a las oficinas profesionales como Módulo de Oscar Niemeyer y ARQUITECTURA de Mario Pani. Justamente esta última fue sin dudas la revista de mayor relevancia y duración en un México que ha editado numerosos títulos, pero en general de corta vida. Cabe de todos modos señalar que el notable trabajo de Carlos Ríos Garza en la UNAM nos está brindando ya más de una docena de DVD con diferentes revistas mexicanas digitalizadas.

Vida efímera tuvieron revistas que jugaron un papel importante en la difusión y comunicación 
del pensamiento renovador en nuestro continente. Fue este el papel que cumplió EL ARQUITECTO en Argentina con el neocolonial o Espacios en México e INTEGRal en Venezuela con el Movimiento Moderno. Un rol similar asumiría la prédica de Nuestra ARQUitectura en Argentina y la del INVI en Chile respecto de la Vivienda, EURE de Chile y Urbana de Venezuela, respectivamente con referencia al urbanismo, aunque está última al editar su número 40 pasará a formato digital.

Dos revistas estudiantiles se proyectaron en el tiempo. Los editores de Trazo en Uruguay continuarían su edición en la revista EL ARQA primero en Montevideo y luego en México. Por su parte Jesús Yepes que iniciara Entre RAYAS en su época de estudiante ha continuado, hasta nuestros días en Caracas, la edición para el sector profesional en una tirada que supera a las antiguas ediciones de revistas en su país.

El siglo xx nos legó también la primicia de las «páginas de arquitectura» de los periódicos. Comenzaron saliendo como rotograbados o suplementos en LA PRENSA y LA NACIÓn de Buenos Aires y en El EXPREso de México y se han ido generalizando en el continente en muchos países y ciudades. Su aparición semanal introdujo nuevamente los temas de la arquitectura y la ciudad a una considerable masa de lectores interesados por las novedades de la profesión. Los temas de arquitectura llegan a un público mucho más amplio que el consumidor habitual de las revistas e introducen referencias sobre un conjunto de obras que muchas veces están teñidas del carácter comercial de quien financia el suplemento con sus avisos.

Estos suplementos tuvieron dispar fortuna, atados a las circunstancias de su financiamiento y por ende a los altibajos inmobiliarios que han caracterizado las últimas décadas. Algunos de ellos desaparecieron y otros fueron a más como el diario CLARín, el de mayor circulación en la Argentina, que realiza ahora $A R Q$, una revista semanal, y ha editado colecciones de Guías de Arquitectura de diversas ciudades del continente y también de series de libros sobre historia de la arquitectura.

Una mención de singular importancia cabe hacer a los medios de comunicación informática que han crecido notoriamente en nuestro siglo XXI. El caso más notable es, sin dudas, el de la eficaz y excelente gestión que realizara Abilio Guerra con su portal VITRUVIUS desde Brasil. Comenzó hace años con la revista Oculum en Campinas y luego a continuado con su portal -el más visitado del continente con miles de seguidores- y su editorial paulista. Un trabajo de singular mérito que van paulatinamente complementando otros portales y blogs de arquitectos y periodistas que tejen notables redes de difusión en la arquitectura.

Quisiera hacer una última referencia al papel creciente que ha tomado el diseño gráfico en la producción de las revistas de arquitectura. Hemos visto surgir algunas de ellas exitosas como ARQ de la Pontificia Universidad Católica de Chile o Croquis de España, revistas que parecían efímeras publicaciones de bajo costo, sin embargo, ellas lograron consolidarse y afianzarse a desmedro de sus iniciales precariedades basadas en las limitaciones de recursos económicos, y sustentadas en sus propuestas inteligentes y atractivas. Pueden entenderse inclusive propuestas lúdicas como la de Portafolio de Maracaibo que nos incita a leer la revista al derecho y al revés para comprender las dos secciones de la misma.

Esto contrasta con revistas armadas sobre la base de un despliegue gráfico excesivo donde el diseñador apuesta a convertir cada página en una «obra de arte» diagramada por ende diferencialmente. En general, esta actitud arrogante donde importa más la presentación que el contenido, no solamente ha causado dificultades en la comunicación sino también que ha asegurado el carácter efímero de la revista. Revistas como DESPACIO de Uruguay muestran significativamente este denodado esfuerzo por la singularización del objeto, antes que la preocupación por aportar en su continente. Una similar observación podemos hacer a la intervención sobre las páginas escritas que suelen intrusarse con rayas y sombras, cuando no se colocan fotos superpuestas o solarizadas que impiden la correcta lectura.

El tratamiento de la fotografía como documentación es otro de los elementos que sufren en muchos de estos nuevos diseños. A veces se opta por el sistema "zapping» de pequeñas fotitos tamaño estampilla que deben pasarse rápidamente para adquirir presencia y movimiento, ya que carecen de toda otra capacidad comunicativa. Otras veces las fotografías prescindiendo de su carácter documental son obliteradas, mutiladas, rebajadas o intervenidas, sin respeto por su mensaje ni por el criterio de su selección. Las facilidades que ha posibilitado el trabajo de las computadoras nos está evidenciando riesgos en la calidad de ciertos productos sin que la crítica se haya hecho sentir a los niveles adecuados.

Esperando la consolidación de revistas de mayor aliento en su presencia en este siglo XX saludamos que las nuevas generaciones de arquitectos, periodistas y editores realicen las adecuadas innovaciones sin perder de vista el basamento de las anteriores experiencias y que le den continuidad a sus esfuerzos. 